\title{
Back out or hang on? An event history analysis of withdrawal from doctoral education in Germany
}

\author{
Steffen Jaksztat ${ }^{1} \cdot$ Martin Neugebauer $^{2} \cdot$ Gesche Brandt $^{1}$
}

Accepted: 11 January 2021 / Published online: 24 June 2021

(c) The Author(s) 2021

\begin{abstract}
Despite the benefits of a PhD for degree-holders as well for society as a whole, doctoral student attrition is a common phenomenon. Unfortunately, the empirical literature on dropout from doctoral education is scant, especially for non-US countries - an omission we address in the current study. Building on Tinto's model of student attrition and rational choice theory, the study empirically assesses the association of different individual, institutional, and external factors with the propensity to leave doctoral studies. Unlike most studies in the field, it draws on longitudinal data using event history modelling, observing doctoral students in multiple disciplines and a wide range of universities. The key results can be summarized as follows: In Germany, women are more likely to dropout than men. The probability of dropping out strongly depends on the discipline and the availability of a scholarship. A close contact with the supervisor and exchange with other PhDs are associated with a lower dropout probability. Moreover, having children increases dropout rates. The study findings provide first empirical guidance for interventions that can possibly help reducing dropout.
\end{abstract}

Keywords Dropout $\cdot$ Attrition $\cdot$ Doctoral education $\cdot \mathrm{PhDs} \cdot$ Event history analysis

\section{Introduction}

Doctoral education has expanded tremendously over the last decades in OECD countries (Auriol, 2010; Enders, 2004). In Germany, the country of interest in this paper, 173.779 persons have been pursuing a doctorate in 2018 (Federal Statistical

Steffen Jaksztat and Martin Neugebauer contributed equally to this work.

Steffen Jaksztat

jaksztat@dzhw.eu

Martin Neugebauer

martin.neugebauer@fu-berlin.de

Gesche Brandt

g.brandt@dzhw.eu

1 German Centre for Higher Education Research and Science Studies (DZHW), Hannover, Germany

2 Freie Universität Berlin, Berlin, Germany 
Office, 2019). Followed by the United Kingdom, Germany is known to be "Europe's biggest producer of doctoral graduates" (Cyranoski et al., 2011: 278). Achieving a $\mathrm{PhD}$ is attractive: A doctoral degree is not only an entry ticket to an independent research career, it is also associated with higher life-time earnings, employment rates, and occupational positions (OECD, 2015; Mertens \& Röbken, 2013; Trennt \& Euler, 2019). At the level of societies, doctorate holders can be considered a crucial factor for the research and innovation capacity of a country (Auriol, 2010; GarciaQuevedo et al., 2012).

Despite these benefits, pursuing a doctorate can be hard, lonely, and frustrating work, and many students leave doctoral education prior to receiving a degree (Consortium for the National Report on Junior Scholars, 2017; Bair \& Haworth, 2004). This is problematic on several levels: For an individual, withdrawal often implies a loss of career opportunities. For universities, a high dropout rate means an inefficient use of facilities and space, and it can endanger the success of research projects. For societies, it may lead to a loss of innovation-relevant scientific knowledge and reduce the building of a scientific workforce, necessary to meet the various global challenges of today.

But which factors contribute to doctoral attrition and what can be done to reduce its occurrence? The vast majority of the literature addressing this question is based on US data, as Bair and Haworth (2004) document in their review. These studies point to a variety of variables associated with doctoral student dropout, including individual level attributes, such as gender, but also institutional experiences, such as the quality of the relationship between doctoral student and advisor, and external factors, such as family obligations (Ehrenberg et al., 2007; Ampaw \& Jaeger, 2012). While illuminating, only few studies exist that incorporate these different factors into a single study, or that develop a coherent theoretical framework to explain their effects. Furthermore, most research in the field is restricted to single institutions or fields of study, making it difficult to generalize findings or to explore variation over institutions (Bair \& Haworth, 2004: 490-91). Compared to research on undergraduate students, longitudinal studies on withdrawal of doctoral students at multiple institutions and in multiple disciplines are rare (Most, 2008).

Fewer studies address the factors associated with doctoral completion among non-US countries (see Geven et al., 2018; Castelló et al., 2017; Skopek et al., 2020; Wollast et al., 2018; Vassil and Solvak 2012 for recent examples). Such studies are important, because national specifics are likely to influence the doctoral experience (Maloshonok \& Terentev, 2018), and findings are not necessarily transferable across countries. For Germany, descriptive evidence suggests that dropout rates vary between fields of study (Euler et al., 2018), and that withdrawal may be higher among women and doctoral students from lower educated families (Lörz \& Mühleck, 2018; Lörz \& Schindler, 2016). However, the few existing studies do not exclusively focus on $\mathrm{PhD}$ dropout, and do not offer in depth analyses in theoretical and empirical manner. Quantitative studies exploring other factors associated with dropping out are virtually non-existent. This is unfortunate, as such an analysis is crucial to better understand the reasons for withdrawal, to provide empirical guidance for institutions, and, ultimately, to help retain more students until degree completion.

Against this background, this study aims to add to the literature in several ways. It develops a theoretical framework that helps to integrate the scattered variables that have been shown to be associated with doctoral student departure. It empirically assesses the association of different pre-entry, institutional, and external factors with the propensity to leave doctoral studies. Unlike most studies in the field, it draws on longitudinal data using 
event history modelling, and it observes doctoral students in multiple disciplines and multiple institutions allowing for generalizations beyond the local contexts. To our knowledge, it is the first quantitative study that systematically analyzes doctoral (non-)completion in Germany.

\section{Theoretical considerations and previous research}

Unlike student attrition, research on doctoral attrition has not been guided by much theoretical considerations (Tinto, 1993: 231). We suggest that similar to attrition during university studies, attrition at the doctoral stage can be conceived as a process in which doctoral students decide to stay or leave. Tinto (1993), in his seminal work on undergraduate student attrition, argues that students are equipped with a set of pre-entry attributes, such as prior schooling outcomes and family background, which influence their ability to integrate into the academic and social system of a higher education institution, and ultimately their decision to drop out. Institutional experiences depend not only on pre-entry attributes but also on institutional factors, such as the amount of intellectual stimulation, or the security of funding. In addition, factors external to the institution affect the decision to leave, for example, family obligations (Tinto, 1993).

More recently, rational choice theory has been proposed to enhance the understanding of study success at the undergraduate level (Beekhoven et al., 2002). Putting an even stronger emphasis on individual choices than Tinto, this theory assumes that students evaluate the available alternative choices, staying or leaving, by considering the probability of success as well as the costs and benefits associated with these choices. If the subjective "utility" of leaving is higher compared to staying, a student leaves. The basic concepts and predictions of rational choice theory coincide well with Tinto's general idea. For example, from a rational choice perspective, positive peer-interactions (i.e., social integration in Tinto's words) increase the subjective benefits of persisting in terms of enjoyment. Similarly, higher performance (i.e., academic integration) increases the probability to successfully complete the degree.

Decisions to leave or continue doctoral training are shaped by the national context in which they occur. Therefore, findings from international studies are not necessarily transferable to the German context, which is characterized by some national specifics. Unlike the US system, where doctoral candidates are selected in a formalized process, German doctoral students are often selected informally by a single professor, who is also the supervisor of the thesis (Hüther \& Krücken, 2018). Possibly, these different recruitment processes lead to a rather heterogeneous pool of doctoral candidates in terms of motivations and scholastic abilities, with potential implications for dropout propensity. Moreover, while there is a clear trend towards giving doctoral education more structure, only a minority of German doctoral students attends a US type graduate school with a structured curriculum (Consortium for the National Report on Junior Scholars, 2017). Instead, the vast majority of doctoral students is employed in fixed-term, part-time positions at chairs or in projects of a professor. This implies not only a strong dependence on a single (mostly male) professor, and, in many instances, less support in the form of structured doctoral training and regular feedback by a team of other researchers. Most PhD candidates also have teaching or research obligations, which leaves less time to work on their thesis. Another national specific is that there are hardly any permanent positions below the level 


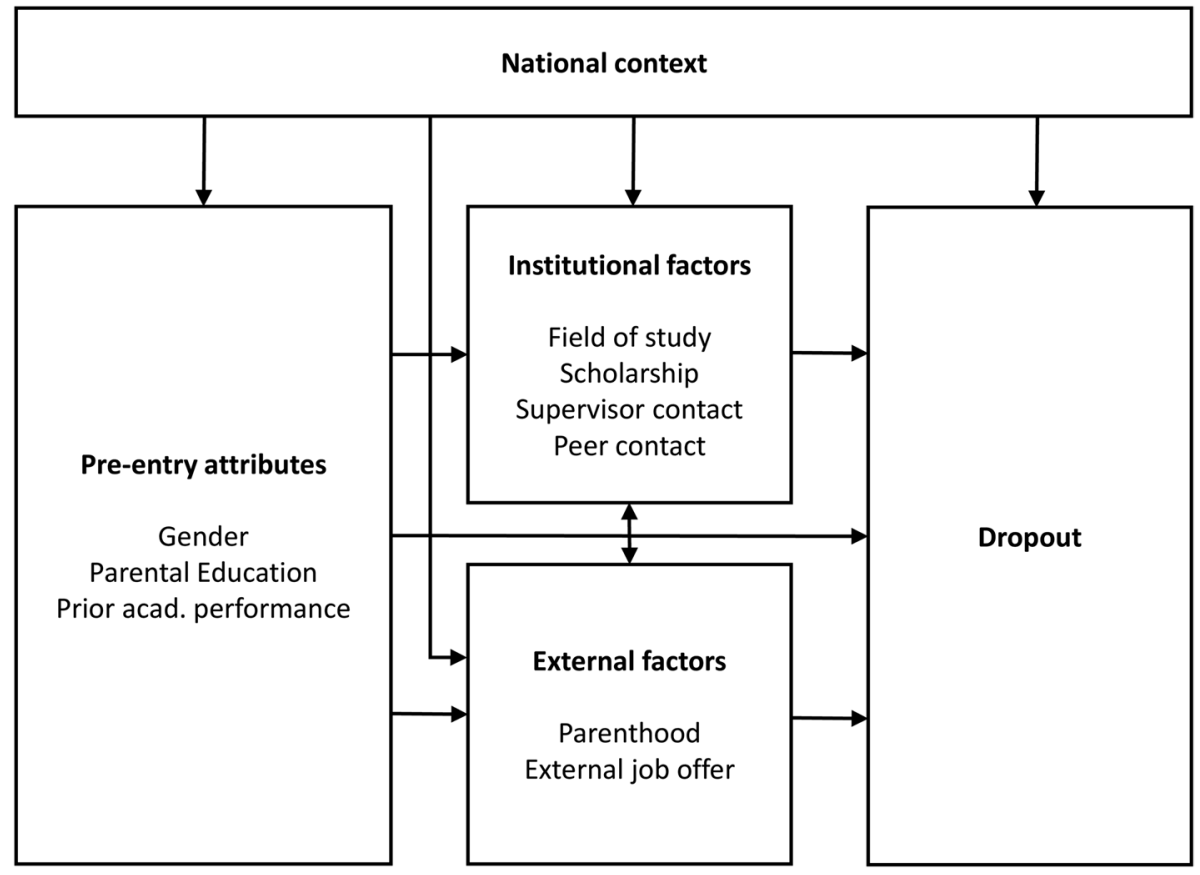

Fig. 1 Theoretical framework

of professor, which is typically achieved around the age of 42 (Hüther \& Krücken, 2018). Compared to other labor market sectors, employment insecurity on the academic labor market is very high.

Drawing on these theoretical premises, the following sections discuss the empirical evidence on pre-entry, institutional, and external (i.e., non-institutional) factors that may influence the propensity to drop out of doctoral studies, and develop hypotheses to explain these associations. Our selection of variables is guided by theoretical considerations but also by data availability. That is to say, we do not develop hypotheses for variables we cannot measure empirically, such as motivational characteristics or the subjectively perceived probability of success. The theoretical framework of our study is presented in Fig. 1.

\section{Pre-entry attributes}

Gender A wealth of studies observed gender gaps in educational outcomes, however, whether males and females experience different dropout patterns from doctoral training, is an empirically open question. According to Bair and Haworth's (2004) review, the majority of studies indicate that gender is not significantly related to doctoral degree completion. This conclusion received confirmation in more recent studies (Mastekaasa, 2005; Wollast et al., 2018; Wright \& Cochrane, 2000; Ampaw \& Jaeger, 2012). However, other studies, including a recent German study, found that men are (slightly) less likely to drop out (Groenvynck et al., 2013; Castelló et al., 2017; Lörz \& Mühleck, 2018; Lott et al., 2009). A reason for these divergent findings may be that studies vary tremendously in their designs and types of samples, with the majority of studies 
relying on data from single institutions or disciplines. Theoretically, we assume that gender-specific dropout rates might be driven by career perspectives for early stage researchers. Given that the division of labor within partnerships is still gender-specific while academic career progression demands a high degree of work engagement and flexibility, women may perceive or anticipate greater work-family-conflicts, making a career in science less attractive to them (Dubois-Shaik \& Fusulier, 2017). Regarding career perspectives, the German higher education system is known to offer particularly insecure employment conditions for early stage researchers due to a lack of tenure track positions (Hüther \& Krücken, 2018). Moreover, female scientists may suffer from subtle evaluation bias in favor of male scientists (Moss-Racusin et al., 2012). Such a bias may be particularly strong in the German system in which the dependence on a single supervisor is particularly strong. Accordingly, a Germany-based study by Jaksztat (2017) suggests that female doctorate holders perceived less promotion and support during their $\mathrm{PhD}$ phase than male doctorate holders. These disadvantages should shape women's decisions to further strive for an academic career and they might decrease their motivation and opportunities to complete a PhD. Accordingly, we expect that women in Germany are more likely to drop out than men (H1).

Parental education Much less attention has been devoted to the social origin of doctoral students. Booth and Satchell (1995) found no effect for parental social class in a sample of British PhD students in the 1980s. For Germany, Lörz and Schindler (2016) reported that students from lower educated families have slightly lower $\mathrm{PhD}$ completion rates, which are primarily caused by differences in academic performance. According to rational choice theory, families try to avoid intergenerational social downward mobility (Breen \& Goldthorpe, 1997). This so-called motive of status maintenance implies social costs of dropping out of doctoral education, but only for those students, whose parents hold doctoral degrees themselves. For all other students, withdrawal would not increase the risk of intergenerational downward mobility. Moreover, parents with doctorates may be better able to support their children financially or with information and tacit knowledge, which raises their success probability. Based on these theoretical considerations, we expect that children whose parents hold a doctorate are less likely to drop out than other doctoral students (H2).

Prior academic performance High levels of prior academic performance are an indicator of high cognitive skills and effort (Schneider \& Preckel, 2017), which should raise the probability of successfully completing a PhD. Contrary to this expectation, Bair and Haworth (2004) concluded in their US review that academic performance indicators are not reliable predictors of persistence to the doctoral degree. For example, only five of fifteen studies found master's Grade Point Average to relate positively to doctoral degree completion. An explanation for these weak findings may be that $\mathrm{PhD}$ students are a highly selective group with only little variance in prior performance. However, an indication that this conclusion may not hold true for non-US countries is given in two Belgium studies (Wollast et al., 2018; Visser et al., 2007) and two German studies (Lörz \& Mühleck, 2018; Lörz \& Schindler, 2016) which found that lower grades are positively associated with dropout. In countries such as Germany, where selection into doctoral studies is less structured and therefore possibly less performance-based, the variance in prior academic performance among PhD candidates may be higher than in the US context. In such a setting, we expect that higher levels of prior academic performance are negatively correlated with the likelihood to drop out (H3). 


\section{Institutional factors}

Subject area Dropout rates differ considerably between subject areas (e.g., Groenvynck et al., 2013; Booth \& Satchell, 1995; Bair \& Haworth, 2004; Wright \& Cochrane, 2000; Euler et al., 2018). The general pattern is that students in the humanities and social sciences are less likely to complete their $\mathrm{PhD}$ than those in natural sciences and medicine. Theoretically, such a pattern is to be expected: following rational choice theory, completion rates should be high in subjects in which the working conditions are more favorable, or where the expected monetary returns of a $\mathrm{PhD}$ are high. Favorable working conditions may be more prevalent in the natural sciences including medicine. Here, research is typically organized in laboratories, where a team of PhD candidates works under direct supervision of an advisor. Such a setting may encourage regular peer exchange and strong supervisory support, even without the structural setting of a graduate school. In the humanities, law, and social sciences, working on a doctoral thesis tends to be less integrated in larger research contexts, possibly leading more frequently to a lack of feedback and feelings of isolation. Moreover, disciplines differ regarding the monetary returns of a PhD. According to a German study by Heineck and Matthes (2012), the returns of a $\mathrm{PhD}$ are the highest in law, engineering, natural sciences, and medicine. Accordingly, we expect for Germany higher dropout rates in the humanities and the social sciences than in law, engineering, natural sciences, and medicine (H4).

Scholarship Funding organizations select their scholars primarily based on previous performance and quality of the suggested $\mathrm{PhD}$ proposal (Nünning \& Sommer, 2007). Therefore, it can be assumed that scholarship holders are a selective group in terms of ability and motivation. Scholarships for PhDs usually cover costs of living for several years, giving students the leeway to focus exclusively on their research project. In addition, funding organizations typically offer mentoring through experienced researchers, and organize networking activities with other PhD students. These factors should increase the success probabilities of doctoral research. Generally, the empirical literature finds that students with secure funding are more likely to succeed (Bair \& Haworth, 2004; Ehrenberg \& Mavros, 1995; Stock et al., 2011; Visser et al., 2007; Wollast et al., 2018). However, it is less clear whether scholarships lead to higher completion rates as opposed to other forms of secure funding (Ampaw \& Jaeger, 2012). Because scholarship programs commonly comprise further aspects beyond funding (selection processes, institutionalized mentoring, and networking), we expect that scholarship holders are less likely to dropout from doctoral studies than other PhD candidates (H5).

Contact with supervisor The supervisor-student relationship is of genuine importance for the success of a doctoral research project (e.g. Mainhard et al., 2009; Skopek et al., 2020). As experts in their fields, they provide intellectual support and information, help their students to establish networks to other researchers, and are supportive in case of difficulties. Furthermore, they can serve as role models, give emotional support, and create an enjoyable working environment, leading to higher student satisfaction. It has been shown repeatedly that positive and frequent contact between advisor and student is a crucial aspect of doctoral completion, while a lack of interaction and support increases the dropout propensity (e.g., Golde, 2005; Lovitts, 2001; Bair \& Haworth, 2004; Castelló et al., 2017; Ampaw \& Jaeger, 2012). Hence, we 
expect that a strong and positive relationship with a supervisor has a negative effect on doctoral dropout (H6).

Exchange with other PhD students Another important source for intellectual and emotional support are peers. In some cases, contact with other doctoral students may, in part, compensate for poor supervisor contact. Although empirical studies suggest that associations between dropout and student-to-student relationships are not as strong as with student-tosupervisor relationships (Bair \& Haworth, 2004; Golde, 2005), we expect that exchange with other PhD students is negatively correlated with drop out from doctoral education (H7).

\section{External factors}

Parenthood Having children potentially implies a restriction of time-resources that are available for other life areas such as doing research. Qualitative studies suggest that having children makes it considerably more difficult to balance home and academic demands, particularly for female PhDs (e.g., Lynch, 2008). Because a career in science requires a high degree of flexibility and the willingness to be geographically mobile, this career path might appear less attractive after the birth of a child. In addition, $\mathrm{PhD}$ positions may offer limited coverage of the higher cost of living typically associated with parenthood. Empirically, several US studies indicate that the number of children does not correlate with attrition (see Bair \& Haworth, 2004). However, the timing of birth may be important. Mastekaasa (2005) found with Norwegian data that children born before the commencement of the $\mathrm{PhD}$ have no impact on attrition. Children born while enrolled have a clear negative effect on the probability of completion among female researchers. Negative parenthood effects were also found for Germany (Lörz \& Mühleck, 2018). We therefore expect that doctoral students with children are more likely to drop out (H8). ${ }^{1}$

Permanent employment offer In Germany, individuals striving for a research career at a university usually have to deal with long periods of employment insecurity (Hüther \& Krücken, 2018). Doctoral students almost always work in fixed-term, part-time positions. Against this background, getting a permanent employment outside academia might be an attractive opportunity for many doctoral students. As such a position might decrease time and motivation to work on the $\mathrm{PhD}$ thesis, we expect that doctoral students receiving a permanent employment offer outside of academia are more likely to drop out from doctoral education (H9).

\section{Selection, mediation, and cumulative risk factors}

To this point, we have derived hypotheses on direct effects of each theoretical component. However, our theoretical framework (Fig. 1) suggests that the theoretical components might be interrelated leading to selection effects and possible mediating mechanisms. For example, students from highly educated families are more likely to choose medicine than students from lower-educated families (Becker et al., 2010). Medicine, in turn, is expected to produce low dropout rates. We therefore expect that the choice of subject will at least partly explain the effects of parental education on dropout. Another

\footnotetext{
1 Due to the low proportion of parents among doctoral students in our data, we do not examine timing effects.
} 
example for possible mediation concerns scholarships. Because of the performancebased criteria for awarding scholarships, we expect that scholarships will at least partly mediate the effect of prior grades. Similarly, the degree of positivity of the supervisor-student relationship may be partly driven by a student's ability and motivation. To address these issues, our multivariate models control for ability, field of study, and other observables (see subsequent section). While not the focus of this paper, we will discuss some of the mentioned interrelations below. However, we do not control for unobserved differences, and want to stress that our findings are descriptive, not causal.

Finally, some students are likely to be affected by several dropout risk factors at the same time, which makes them particularly vulnerable to non-completion. In the last part of the empirical analyses, we adopt a person-centered approach to illustrate the degree to which cumulative risk factors may increase the dropout propensity.

\section{Methods}

\section{Data}

We use data from a panel study of university graduates that was conducted by the German Centre for Higher Education Research and Science Studies (DZHW) between 2006 and 2016 (https://doi.org/10.21249/DZHW:gra2005:2.0.0). The target population of the survey were individuals from all subject areas who successfully completed their first degree ${ }^{2}$ at a German university in 2005 (for details, see Baillet et al., 2019). The panel survey consists of three waves that were conducted approximately 1 year $(N=10,165$; response rate $24.7 \%), 5$ years $(N=5674 ; 60.5 \%)$, and 10 years $(N=3760 ; 66.3 \%)$ after graduation. ${ }^{3}$ Following wave three, the DZHW additionally carried out an in-depth survey among respondents who had started a doctorate within the observation period. Data collection was based on standardised self-administered paper-pencil-questionnaires (waves 1 and 2) and standardised self-administered online questionnaires (wave 3 and in-depth survey).

For the purpose of our analysis, we use a subsample of graduates who indicated in one of the survey waves that they had started a doctorate after graduation (2035 cases). Because information on scholarships as well as supervisor and peer contact have been collected in wave 2 and in the in-depth survey, our analytical sample is further restricted to individuals who have participated in at least one of these follow-up waves (1369 cases). After excluding individuals with missing data, the analytical sample comprises 1226 cases. Item-nonresponse varies between 0 and 4.75 percent. In order to reduce the risk of biased estimates that might occur through systematic panel attrition, we adjust the sample by using panel weights provided by the DZHW.

\section{Variables}

Our dependent variable is dropout from doctoral education. In all waves, respondents were asked whether they were currently doing a doctorate, have already completed a doctorate, or have stopped doing a doctorate without completion. Additionally, doctoral holders and

\footnotetext{
2 i.e., diploma, Staatsexamen, or magister atrium.

${ }^{3}$ Response rates for waves 2 and 3 refer to individuals who had agreed to further participate in the survey.
} 
Table 1 Variable description

\begin{tabular}{|c|c|c|c|c|}
\hline Component & Variable & Description & Categories & $\begin{array}{l}\text { Per cent / } \\
\text { mean }(\mathrm{SD})\end{array}$ \\
\hline \multirow{8}{*}{$\begin{array}{l}\text { Pre-entry } \\
\text { attributes }\end{array}$} & \multirow[t]{2}{*}{ Gender } & \multirow[t]{2}{*}{ Respondent's gender } & Male & 51.5 \\
\hline & & & Female & 48.5 \\
\hline & \multirow[t]{3}{*}{ Parental education } & \multirow{3}{*}{$\begin{array}{l}\text { Parents' highest vocational } \\
\text { degree }\end{array}$} & Non-academic & 36.8 \\
\hline & & & $\begin{array}{l}\text { Father/mother with } \\
\text { (under)graduate degree }\end{array}$ & 44.5 \\
\hline & & & $\begin{array}{l}\text { Father/mother with } \\
\text { doctoral degree }\end{array}$ & 18.7 \\
\hline & $\begin{array}{l}\text { High school graduation } \\
\text { grade }\end{array}$ & $\begin{array}{l}\text { Final grade at high school; } \\
\text { z-standardized; reverse coded }\end{array}$ & mean & $\begin{array}{c}0.00 \\
{[100]}\end{array}$ \\
\hline & \multirow{2}{*}{$\begin{array}{l}\text { University graduation } \\
\text { grade }\end{array}$} & \multirow{2}{*}{$\begin{array}{l}\text { Final grade at university; } \\
\text { z-standardized by subject area; } \\
\text { reverse coded }\end{array}$} & mean & 0.00 \\
\hline & & & (SD) & [1.00] \\
\hline \multirow{13}{*}{$\begin{array}{l}\text { Institutional } \\
\text { factors }\end{array}$} & \multirow[t]{7}{*}{ Subject area } & \multirow{7}{*}{$\begin{array}{l}\text { Subject area of the university } \\
\text { degree }\end{array}$} & Humanities & 10.2 \\
\hline & & & Social Sciences & 15.7 \\
\hline & & & Law & 8.6 \\
\hline & & & Math/Natural Sciences & 23.4 \\
\hline & & & Medicine & 24.3 \\
\hline & & & Engineering & 9.4 \\
\hline & & & Others & 8.3 \\
\hline & \multirow[t]{2}{*}{ Scholarship } & \multirow{2}{*}{$\begin{array}{l}\text { Having received graduate fund- } \\
\text { ing or other scholarship during } \\
\text { the doctorate }\end{array}$} & No & 80.7 \\
\hline & & & Yes & 19.3 \\
\hline & \multirow{2}{*}{$\begin{array}{l}\text { Close contact with } \\
\text { supervisor }\end{array}$} & \multirow{2}{*}{$\begin{array}{l}\text { Close working contact with the } \\
\text { supervising professor while } \\
\text { writing doctoral thesis }\end{array}$} & No & 50.9 \\
\hline & & & Yes & 49.2 \\
\hline & \multirow{2}{*}{$\begin{array}{l}\text { Exchange with other } \\
\text { PhDs }\end{array}$} & \multirow{2}{*}{$\begin{array}{l}\text { Professional contact with other } \\
\text { doctoral students while writing } \\
\text { doctoral thesis }\end{array}$} & No & 56.4 \\
\hline & & & Yes & 43.6 \\
\hline \multirow{4}{*}{$\begin{array}{r}\text { External } \\
\text { factors }\end{array}$} & \multirow[t]{2}{*}{ Parenthood ${ }^{1)}$} & \multirow{2}{*}{$\begin{array}{l}\text { Having one or more children; } \\
\text { time-varying }\end{array}$} & No & 94.2 \\
\hline & & & Yes & 5.8 \\
\hline & \multirow{2}{*}{$\begin{array}{l}\text { Permanent } \\
\text { Employment }{ }^{1)}\end{array}$} & \multirow{2}{*}{$\begin{array}{l}\text { Having a permanent employment } \\
\text { contract; time-varying }\end{array}$} & No & 92.6 \\
\hline & & & Yes & 7.5 \\
\hline
\end{tabular}

${ }^{1)}$ Proportions at the beginning of the doctorate

Data: DZHW Graduate Panel 2005 (conducted between 2006 and 2016)

(former) doctoral students were asked when they had started their doctorate and when they had possibly completed or dropped out. It was left to the respondents to define the events they considered to be the beginning and end of their doctorate. In case of missing date information, we additionally used monthly based episode data that were included in the survey. The start of a doctorate can occur at any time during the 10-year observation window after graduation, except for medical students, who commonly begin working on a doctoral thesis before graduating from medical studies.

All independent variables are presented in Table 1. Pre-entry attributes comprise respondents' gender, parental education, and high school and university graduation grades. Grades are z-standardized and reverse-coded so that higher values indicate better grades. We operationalize the institutional context by four variables: subject area, 
funding of the doctorate through a scholarship, having a close contact with the supervisor and being in exchange with other PhDs. ${ }^{4}$

External factors comprise the time-varying variables parenthood ${ }^{5}$ and permanent employment. The variable permanent employment indicates whether and when an individual received a permanent employment contract during the doctoral phase. Unfortunately, we are not able to specify the corresponding employment sector with our data (i.e., inside or outside academia). Because permanent positions for doctoral students hardly exist at German research institutions, we assume that a permanent employment contract implies a job outside academia and use this variable as a proxy.

\section{Statistical methods}

To test our hypotheses, we use cox proportional hazard models. First of all, this method allows us to handle right-censored data. Episodes start with the beginning of the doctorate and end with one of the following events: dropout, completion or censoring, i.e., doctorate ongoing. Every sixth observation in our sample is right-censored, meaning that we do not know whether these individuals will ultimately drop out or successfully complete their $\mathrm{PhD}$. In contrast to conventional regression analysis, event history analysis allows us to include these incomplete observations in our models thereby using the full information available to estimate covariate effects. Furthermore, this method allows us to take advantage of the longitudinal structure of our data by introducing time-varying variables in our models such as parenthood and receiving a permanent employment contract. Although the focal event of our analysis is a dropout from doctoral education, we additionally calculate cause-specific hazards for the competing event, i.e., successful completion. Unfortunately, cause-specific cox regressions have the disadvantage that there is no "one-to-one correspondence between cumulative incidence and cause-specific hazard" (Andersen et al., 2012: 865). Cause-specific hazard ratios do not necessarily reflect the corresponding covariate effects on risks, because individuals experiencing the competing event are removed from the risk set as if they were right-censored. As suggested by Latouche et al. (2013), we therefore also calculate Fine-Gray subdistribution hazard regressions (Fine \& Gray, 1999) which "directly link the cumulative incidence to explanatory variables" (Andersen et al., 2012: 867). However, a disadvantage of this method is that the possibility of including time-varying covariates is limited (Austin et al., 2020). Since our analytical model contains two time-varying variables (parenthood and permanent employment), hypothesis tests are mainly based on cox regressions. Fine-Gray regressions are additionally used to illustrate covariate effects on the cumulative incidence function of dropout.

In the following section, we first describe the frequency and timing of events. Subsequently, we test our hypotheses in cox proportional hazard models and compare the results with the

\footnotetext{
4 The variables "close contact with supervisor" and "exchange with other PhDs" are based on respondents' subjective assessment of how they have interacted with others while writing their doctoral thesis. Unfortunately, answer scales of these questions differed between the waves. Wave 2 contained dichotomous answer scales (yes/no) whereas the in-depth survey contained a five-point-scale ranging from $1=$ "applies completely" to $5=$ "applies not at all". In order to harmonize variables, we had to apply top-box-coding $(1+2=$ yes; $3+4+5=$ no $)$.

${ }^{5}$ Due to the low proportion of doctoral students with children, we do not test possible interaction effects with gender.
} 
alternative Fine-Gray model. Finally, we adopt a person-centred approach and illustrate how sets of risk factors cumulate to pronounced group differences in dropout probabilities.

\section{Results}

\section{Description of events}

In our sample, $71 \%$ successfully completed their doctorate while 13\% dropped out (Fig. 2). Seventeen percent of cases are right-censored which means that they were still doing their doctorate at the time of the last interview. These are mainly doctoral candidates who did not participate in the survey after the second wave, as well as people who started their doctorate late or have a long doctoral period.

Successful completion of the doctorate occurs relatively late. The envisaged length in Germany is 3 years, which is the typical funding period for doctoral candidates in research projects or at chairs. Interestingly, however, the middle $50 \%$ of all completers needed between 41 and 66 months until degree completion. The average time-to-completion is 55 months $(\mathrm{SD}=22)$, i.e., four and a half years. In comparison, dropout from doctoral education typically occurs earlier. The middle $50 \%$ of non-successful doctoral students dropped out within 16 and 46 months. The average time-to-dropout is 32 months $(\mathrm{SD}=24)$.

\section{Cause-Specific cox regression}

In order to explore associations between the independent variables and the dropout propensity, we first of all conducted cox regressions for each independent variable separately. In a second step, we included all independent variables into one model in order to learn more about their interrelations and their relative importance. Table 2 in the appendix additionally contains separate cox regressions models for each of our three theoretical components, and a model for the competing event (i.e., successful completion).

Our analysis shows that pre-entry attributes play an important role for dropout (Fig. 3). In line with H1, we find that female doctoral candidates drop out at higher rates than their male colleagues. In line with $\mathbf{H 2}$, we find that individuals whose parents have earned a doctoral degree have significantly lower dropout rates compared to individuals from nonacademic families. However, this effect becomes weaker when controlling for the other covariates, and it is sensitive to model specification. In-depth analyzes-which are not presented here-suggest that the parental education effect is partly mediated by subject choices. Individuals from a highly educated families are more likely to study medicine which is a subject with particular low dropout rates. Turning to $\mathbf{H 3}$, it becomes evident that better school grades and university grades are negatively associated with dropout. However, the effects of both variables decrease in our full model, and only the effect of the university grade remains marginally significant.

In line with our theoretical assumptions, the likelihood of dropping out is related to the institutional context. The dropout rates significantly vary between the subject areas (H4). Compared to the reference group humanities, individuals from math/natural sciences, medicine, and engineering have lower dropout rates. Contradicting our theoretical assumptions, 

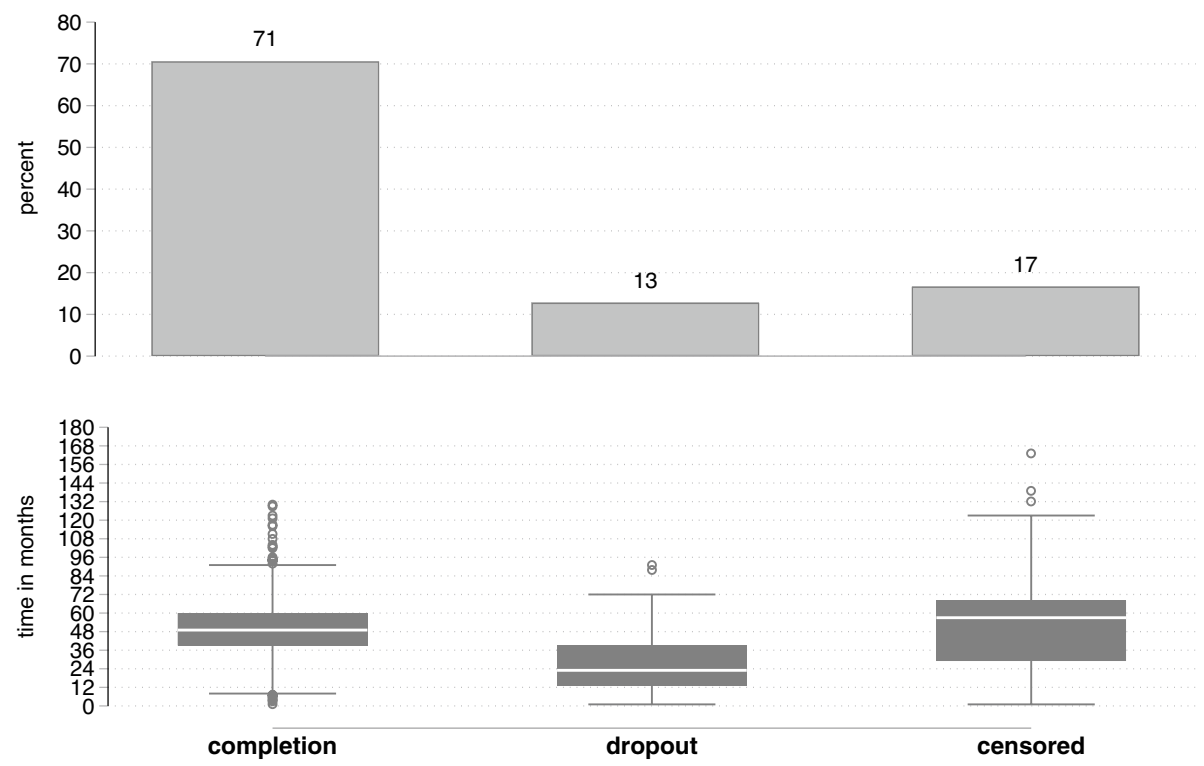

Fig. 2 Frequency and timing of events. Data: DZHW Graduate Panel 2005 (conducted between 2006 and 2016)

dropout rates in law do not significantly differ from those in the humanities. In line with H5, receiving a scholarship is associated with a lower risk of dropping out even under control of performance indicators. We find strong support for the assumption that individuals who are well integrated in academia are less likely to drop out. Supporting H6 and H7, a close contact with the supervisor and exchange with other PhDs are associated with lower dropout rates.

Regarding external context effects, our analysis confirms that doctoral students who already have children or become parents during the $\mathrm{PhD}$ drop out at higher rates (H8). In line with $\mathbf{H 9}$, receiving a permanent employment during the doctorate increases the likelihood of dropping out, yet in the fully specified model, the effect of a permanent employment is no longer significant.

\section{Fine-Gray competing risk regression}

Regarding the cause-specific hazard of the competing event, i.e., successful completion, cox regression estimates indicate that the hazard rate of successful completion is not significantly associated with gender (Appendix Table 2; model 5). This counterintuitive finding results from the fact that the cause-specific hazard of successful completion refers to individuals still at risk. A Fine-Gray competing risk regression, in contrast, takes into account that individuals experiencing the competing event have no chance of experiencing the event of interest in the future by keeping them in the risk set (Fine \& Gray, 1999; Cleves et al., 2016). In fact, the Fine-Gray model suggests that females tend to have a lower probability of successfully completing their doctorate (Appendix Table 3). Taken together, results indicate that the gender effect is mainly indirect, namely, by affecting the cause-specific hazard of dropping out (Latouche et al., 2013). Apparently, women tend to end their 


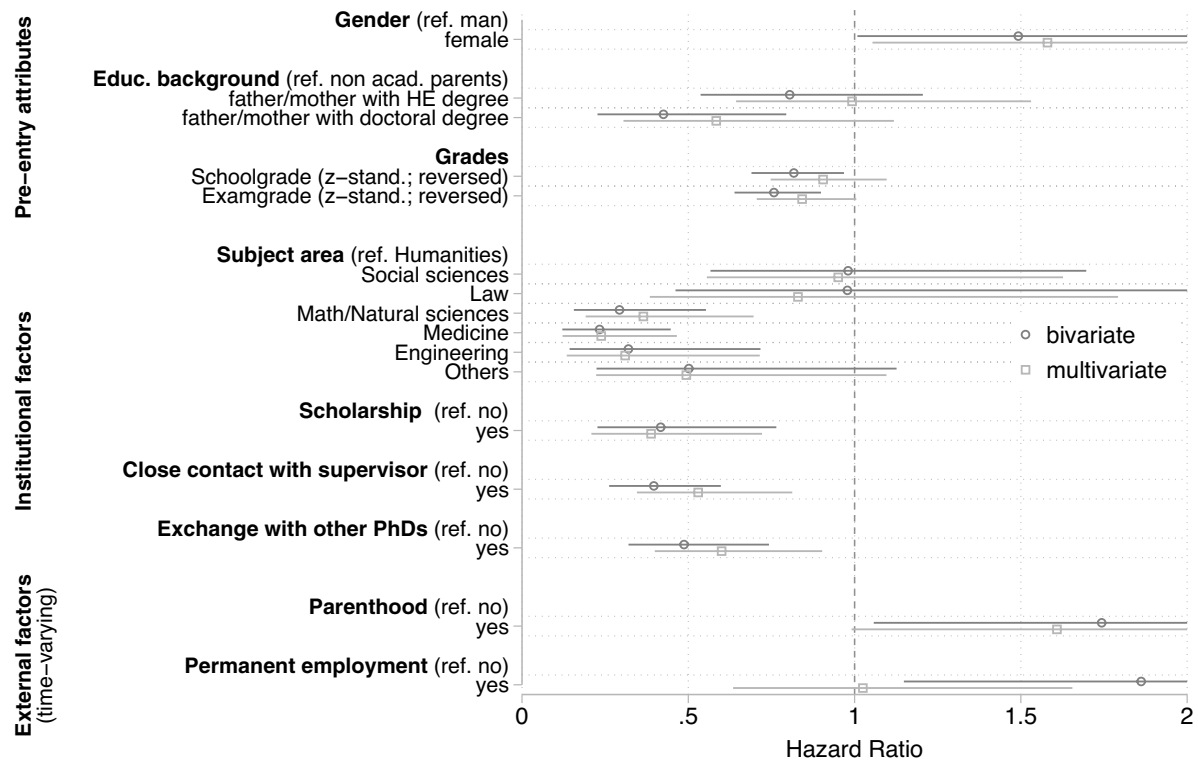

Fig. 3 Factors associated with attrition from doctoral education.Exponentiated coefficients and $95 \%$ confidence intervals from cox regressions. A regression table corresponding with this figure is displayed in Appendix Table 2, model 4. Data: DZHW Graduate Panel 2005 (conducted between 2006 and 2016)

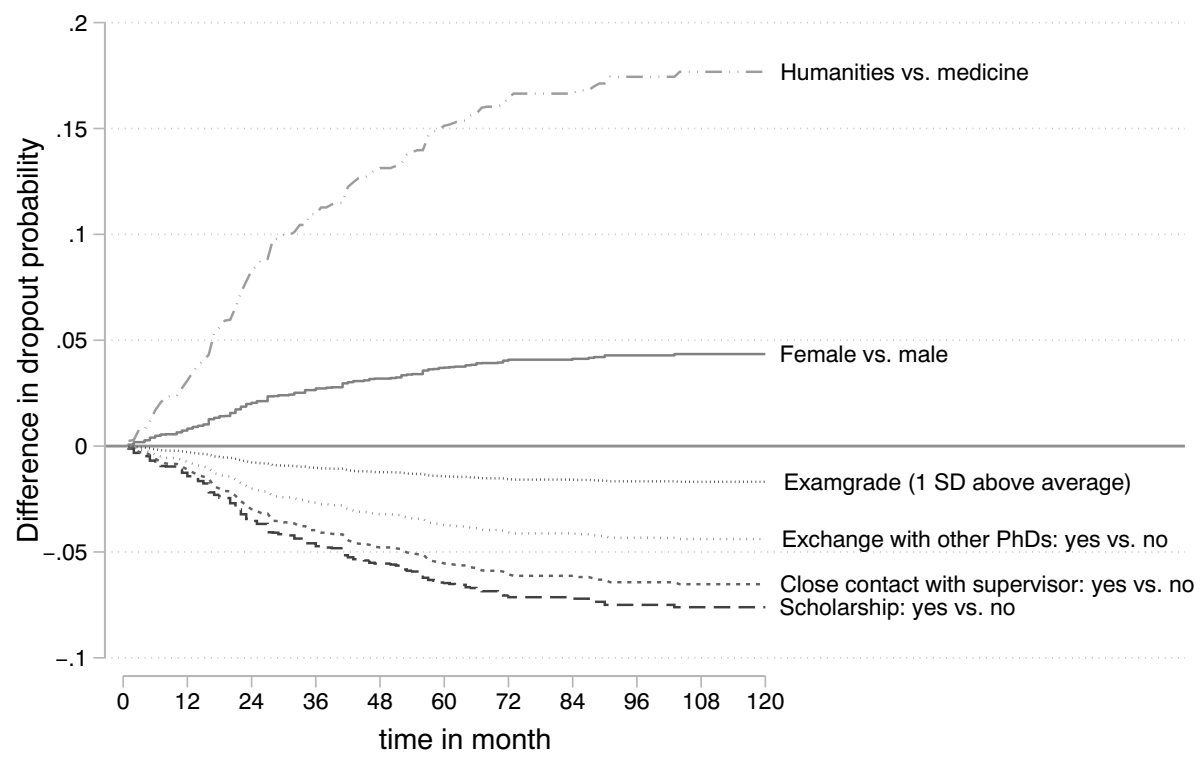

Fig. 4 Covariate effects on cumulative probability of dropout. Differences in predicted probabilities based on model 2 in Appendix Table 3; effects evaluated at the sample average; excluding non-significant variables. Data: DZHW Graduate Panel 2005 (conducted between 2006 and 2016) 
doctorate faster, not because they complete faster, but because they dropout faster. Other covariate effects are largely identical in the Cox model and the Fine-Gray model.

Based on the Fine-Gray model, Fig. 4 quantifies covariate effects on dropout probabilities, reflecting the importance of institutional factors such as the discipline and scholarships, and also pre-entry attributes such as gender (see Skopek et al., 2020 for a similar illustration).

\section{Cumulative risk factors}

The results of the competing risk regression can also be used to compare dropout probabilities of groups with a high respective low-risk profile. Figure 5 illustrates cumulative incidence curves for the subject areas math/natural sciences and humanities. In each subject area, the low-risk group comprises male PhDs, having a close contact with their supervisor, being in exchange with other PhDs and holding a scholarship. The high-risk group comprises female $\mathrm{PhDs}$ who do not have a strong supervisor relationship, who are not in exchange with other PhDs, and who are not funded by a scholarship. In both subject areas, the first group is predicted to have almost negligible dropout rates. However, within math/natural sciences, the cumulative incidence rate for the second group is approximately $7 \%$ after 2 years, $12 \%$ after 4 years and ultimately amounts to $17 \%$. Within the humanities, every fourth individual from the high-risk group is predicted to drop out within 2 years. Here, incidence rates ultimately amount to $48 \%$. These cumulative incidence curves highlight two aspects: Subject areas play a crucial role and the
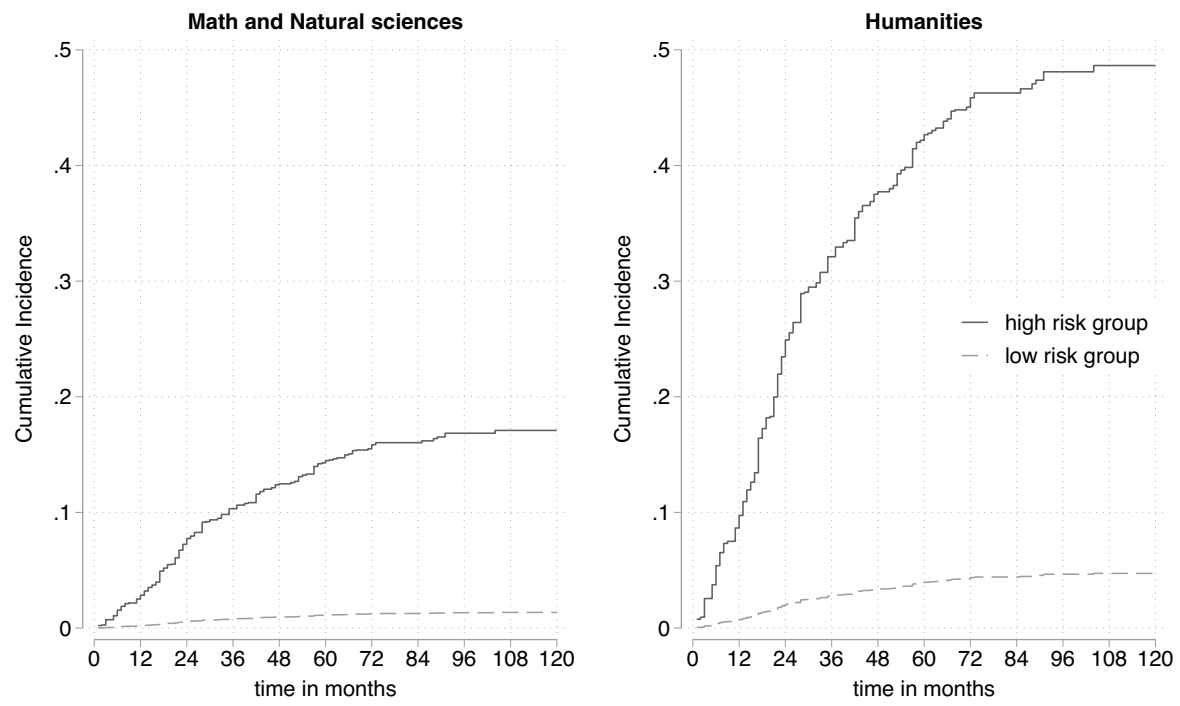

High risk group = female; no close contact with supervisor; no exchange with other PhD; no scholarship Low risk group = male; close contact with supervisor; exchange with other $\mathrm{PhD}$; scholarship

Fig. 5 Predicted cumulative incidence rates of dropout for high and low-risk individuals. Prediction based on model 2 in Appendix Table 3; unlisted covariates set to mean values. Data: DZHW Graduate Panel 2005 (conducted between 2006 and 2016) 
combination of certain risk factors results in pronounced differences in the probability to dropout.

\section{Summary and discussion}

Building on Tinto's (1993) model of student attrition and rational choice theory (Breen \& Goldthorpe, 1997), our study assessed associations of different pre-entry, institutional, and external factors with the likelihood to leave doctoral studies in Germany. Based on a nationally representative 10 -year longitudinal graduate survey with $n=1226$ doctoral students, the key results of our event history analysis can be summarized as follows: Female doctoral candidates are more likely to drop out from doctoral education than their male colleagues, and those with better prior grades are less likely to withdraw. The probability of dropping out strongly depends on the discipline and the availability of a scholarship. Furthermore, integration matters: A close contact with the supervisor and exchange with other $\mathrm{PhDs}$ is associated with a lower dropout probability. Having children increases the dropout rate. The accumulation of these risk factors is associated with a massive increase in the dropout propensity.

To our knowledge, this is the first quantitative study that systematically analyzes doctoral (non-)completion in Germany, Europe's largest producer of doctoral graduates (Cyranoski et al., 2011). While the results are generally in line with the international literature, some notable exceptions deserve further attention. Unlike most countries, gender and parenthood are related to doctoral attrition, which potentially contributes to the reproduction of inequalities. Academic careers in Germany are characterized by a strong dependence on a single (mostly male) supervisor and a high degree of career uncertainty (Hüther \& Krücken, 2018), which may contribute to these findings. Nonetheless, future studies should address questions about the underlying mechanisms (e.g., discrimination or self-selection), the role of disciplinary and institutional contexts, and also about possible social change. Certainly, more information on family structures are needed to accurately assess the impact of children. Another finding that differs from the US-literature is that prior performance is associated with dropout. While further investigation is required, we conjecture that this may be partly driven by a less meritocratic selection into doctorates in Germany.

The study findings provide first empirical guidance for interventions that can possibly help reducing dropout. Interventions may be targeted towards "at-risk groups" such as women, for example, by implementing special mentoring programs. Another "at-risk" group are doctoral students with children, who are likely to experience conflicts between familial obligations and their job demands as scientists. In order to provide more family-friendly conditions for doctoral candidates, universities, policymakers, and funding organizations might consider to increase the financial support for scientists with children, to extend the duration of scholarships and employment contracts, or to ease interruptions and re-entries. Interventions may also address the "integrational" difficulties that many doctoral students experience. Decision-makers at universities should ensure that working contexts of $\mathrm{PhD}$ students provide opportunities to get in contact with experienced researchers and other $\mathrm{PhD}$ students. This might be achieved, for example, by regular colloquia where doctoral candidates can discuss their ideas and problems in an open atmosphere, by supporting team work, by integrating doctoral candidates in larger research projects, by establishing supervision 
by multiple professors, or by training professors to become better supervisors. Moreover, our study has shown that scholarship-holders are less likely to dropout. While scholarship holders are likely to be a selective group in terms of motivation and ability, we assume that the financial security that scholarships offer plays an important role regarding dropout. In order to reduce dropout, universities and research departments should strive to increase employment security among doctoral candidates, for example, by guaranteeing a minimum length of employment contracts that correspond to the length of a typical doctorate.

The main limitations of our study result from using secondary data which has not been collected for the purpose of studying $\mathrm{PhD}$ dropout. This confines our analysis to the variables available in the dataset. For example, we were unable to consider personal characteristics and attitudes (Cooke et al., 1995), or work-related aspects such as teaching obligations. Moreover, our analysis is limited by incomplete information. Because the panel waves did not include the same set of variables, most respondents answered the questions about their supervisor and peer contact after their $\mathrm{PhD}$ phase, which may have biased their answers. The information in the variable "permanent employment" is also incomplete, as it does not specify whether this position was truly outside of academia. Another limitation concerns the self-reported measurement of the start and end points of the doctorate. Recalling the start and the end of the doctorate exactly on the month is probably prone to remembrance errors. Moreover, some respondents might define conceptualizing their thesis as the start, others the beginning of the Ph.D. position. Similarly, in the case of attrition, the end date might be hard to determinate, because dropout can be a longer process (Franz, 2018). However, despite these difficulties in measurement, using available date information allowed us to apply event history modelling which is most suitable in case of censored data. Despite the temporal ordering of variables in this longitudinal study, our results are correlative, not causal. Reversed causality is likely to be an issue: For example, doctoral candidates who have already decided to drop out in the future may be more likely to have children. Probably, they will also be more motivated to actively search for permanent employment outside of academia. Last but not least, certain associations (e.g., regarding subject areas or scholarships) are probably at least partly driven by unobserved selection effects.

In light of the crucial role doctorate degree-holders play for the research and innovation capacity of a country, a deeper understanding of the mechanisms that lead to successful degree attainment is important. To progress, future research should address the mentioned limitations. Fortunately, the German Centre for Higher Education Research and Science Studies has started a research project (National Academic Panel Study) ${ }^{6}$ focusing on the educational and professional pathways of doctoral candidates and doctorate holders that will improve data availability in the future. Future research might therefore be able to address some of the unsolved questions. For example, how do learning environments affect dropout propensities? Which practical measures are appropriate to reduce dropout? Does dropout from doctoral education have a negative impact on career success and life satisfaction at all? Maybe, dropouts are just taking up more attractive opportunities outside academia.

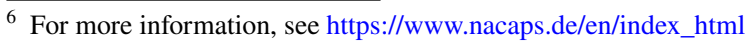




\section{Appendix}

Table 2 Cox proportional hazard models (1-3, separate models for theoretical components; 4 , fully specified model; 5 , fully specified model for successful completion)

\begin{tabular}{|c|c|c|c|c|c|c|c|c|c|c|c|}
\hline & & \multicolumn{2}{|c|}{ (1) Event: dropout } & \multicolumn{2}{|c|}{ (2) Event: dropout } & \multicolumn{2}{|c|}{ (3) Event: dropout } & \multicolumn{2}{|c|}{$\begin{array}{l}\text { (4) Event: } \\
\text { dropout }\end{array}$} & \multicolumn{2}{|c|}{$\begin{array}{l}\text { (5) Event: com- } \\
\text { pletion }\end{array}$} \\
\hline & & $\begin{array}{l}\text { Hazard } \\
\text { ratios }\end{array}$ & SE & $\begin{array}{l}\text { Hazard } \\
\text { ratios }\end{array}$ & $\mathrm{SE}$ & $\begin{array}{l}\text { Hazard } \\
\text { ratios }\end{array}$ & SE & $\begin{array}{l}\text { Hazard } \\
\text { ratios }\end{array}$ & $\mathrm{SE}$ & $\begin{array}{l}\text { Hazard } \\
\text { ratios }\end{array}$ & SE \\
\hline \multirow{9}{*}{$\begin{array}{l}\text { Pre-entry } \\
\text { attributes }\end{array}$} & Gender & & & & & & & & & & \\
\hline & Male & ref & [.] & & & & & ref & {$[]$.} & ref & [.] \\
\hline & Female & $1.56^{*}$ & {$[0.32]$} & & & & & $1.58^{*}$ & {$[0.33]$} & 0.99 & {$[0.08]$} \\
\hline & Educational background & & & & & & & & & & \\
\hline & Non-academic parents & ref & [.] & & & & & ref & {$[]$.} & ref & [.] \\
\hline & $\begin{array}{l}\text { Father/mother with } \\
\text { (under)graduate } \\
\text { degree }\end{array}$ & 0.85 & {$[0.18]$} & & & & & 0.99 & {$[0.22]$} & 0.98 & {$[0.09]$} \\
\hline & $\begin{array}{c}\text { Father/mother with } \\
\text { doctoral degree }\end{array}$ & $0.43^{* *}$ & {$[0.14]$} & & & & & 0.58 & {$[0.19]$} & 1.04 & {$[0.12]$} \\
\hline & $\begin{array}{l}\text { Schoolgrade (z-stand.; } \\
\text { reversed) }\end{array}$ & 0.87 & {$[0.08]$} & & & & & 0.91 & {$[0.09]$} & $1.11^{*}$ & {$[0.05]$} \\
\hline & $\begin{array}{l}\text { Examgrade (z-stand; } \\
\text { reversed) }\end{array}$ & $0.80^{*}$ & {$[0.07]$} & & & & & $0.84^{\#}$ & {$[0.08]$} & $1.11^{*}$ & {$[0.05]$} \\
\hline \multirow{17}{*}{$\begin{array}{l}\text { Institutional } \\
\text { factors }\end{array}$} & Subject area & & & & & & & & & & \\
\hline & Humanities & & & ref & [.] & & & ref & {$[]$.} & ref & [.] \\
\hline & Social sciences & & & 0.88 & {$[0.25]$} & & & 0.95 & {$[0.26]$} & 1.33 & {$[0.26]$} \\
\hline & Law & & & 0.67 & {$[0.26]$} & & & 0.83 & {$[0.33]$} & $2.04^{* * *}$ & [0.47] \\
\hline & Math/Natural sciences & & & $0.33^{* * * *}$ & {$[0.11]$} & & & $0.36^{* *}$ & {$[0.12]$} & $2.11^{* * *}$ & [0.37] \\
\hline & Medicine & & & $0.19^{* * * *}$ & {$[0.06]$} & & & $0.24^{* * * *}$ & {$[0.08]$} & $1.60^{* * *}$ & {$[0.28]$} \\
\hline & Engineering & & & $0.25^{* * * *}$ & {$[0.10]$} & & & $0.31^{* * *}$ & {$[0.13]$} & 1.04 & {$[0.21]$} \\
\hline & Others & & & $0.48^{\#}$ & {$[0.20]$} & & & $0.49^{\#}$ & {$[0.20]$} & $1.53^{*}$ & {$[0.30]$} \\
\hline & Scholarship & & & & & & & & & & \\
\hline & No & & & ref & [.] & & & ref & {$[]$.} & ref & [.] \\
\hline & Yes & & & $0.35^{* * *}$ & {$[0.11]$} & & & $0.39^{* * *}$ & {$[0.12]$} & 1.11 & {$[0.11]$} \\
\hline & $\begin{array}{l}\text { Close contact with } \\
\text { supervisor }\end{array}$ & & & & & & & & & & \\
\hline & No & & & ref & [.] & & & ref & {$[]$.} & ref & [.] \\
\hline & Yes & & & $0.55^{* *}$ & {$[0.12]$} & & & $0.53^{* *}$ & {$[0.12]$} & $1.19^{*}$ & {$[0.10]$} \\
\hline & $\begin{array}{l}\text { Exchange with other } \\
\mathrm{PhD}\end{array}$ & & & & & & & & & & \\
\hline & No & & & ref & [.] & & & ref & [.] & ref & [.] \\
\hline & Yes & & & $0.57^{*}$ & {$[0.12]$} & & & $0.60^{*}$ & [0.12] & 1.00 & [0.09] \\
\hline \multirow[t]{7}{*}{$\begin{array}{l}\text { External } \\
\text { factors }\end{array}$} & $\begin{array}{l}\text { Parenthood (time- } \\
\text { varying) }\end{array}$ & & & & & & & & & & \\
\hline & No & & & & & ref & [.] & ref & {$[]$.} & ref & [.] \\
\hline & Yes & & & & & $1.73^{*}$ & {$[0.44]$} & $1.61^{\#}$ & {$[0.40]$} & 0.87 & {$[0.10]$} \\
\hline & $\begin{array}{l}\text { Permanent Employ- } \\
\text { ment (time-varying) }\end{array}$ & & & & & & & & & & \\
\hline & No & & & & & ref & [.] & ref & {$[]$.} & ref & [.] \\
\hline & Yes & & & & & $1.85^{*}$ & {$[0.46]$} & 1.02 & {$[0.25]$} & 1.01 & [0.12] \\
\hline & $\mathrm{N}$ & 1226 & & 1226 & & 1226 & & 1226 & & 1226 & \\
\hline
\end{tabular}

Exponentiated coefficients; weighted data; ${ }^{\#} p<0.10,{ }^{*} p<0.05,{ }^{* *} p<0.01,{ }^{* * *} p<0.001$

Data: DZHW-Graduate Panel 2005 (conducted between 2006 and 2016) 


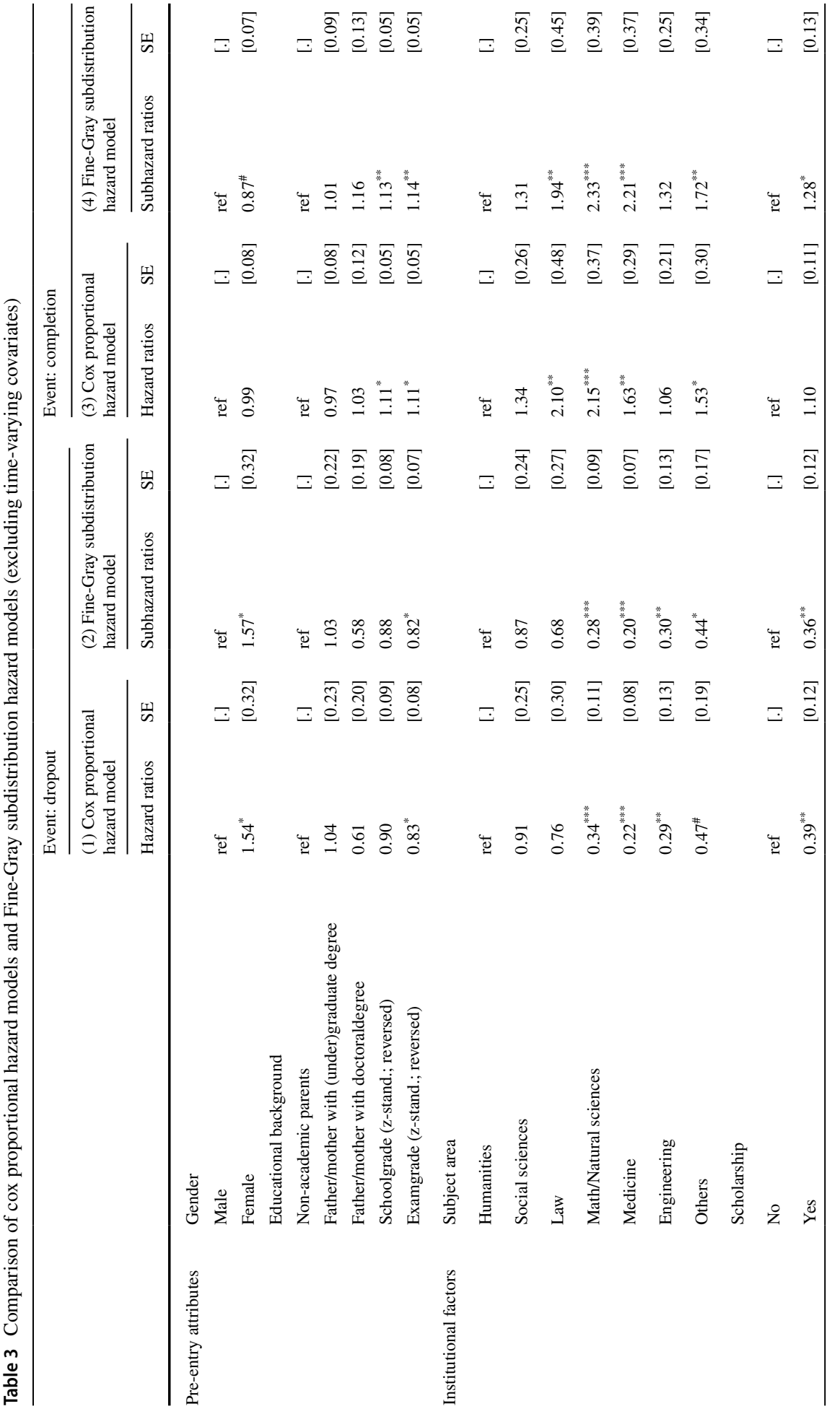




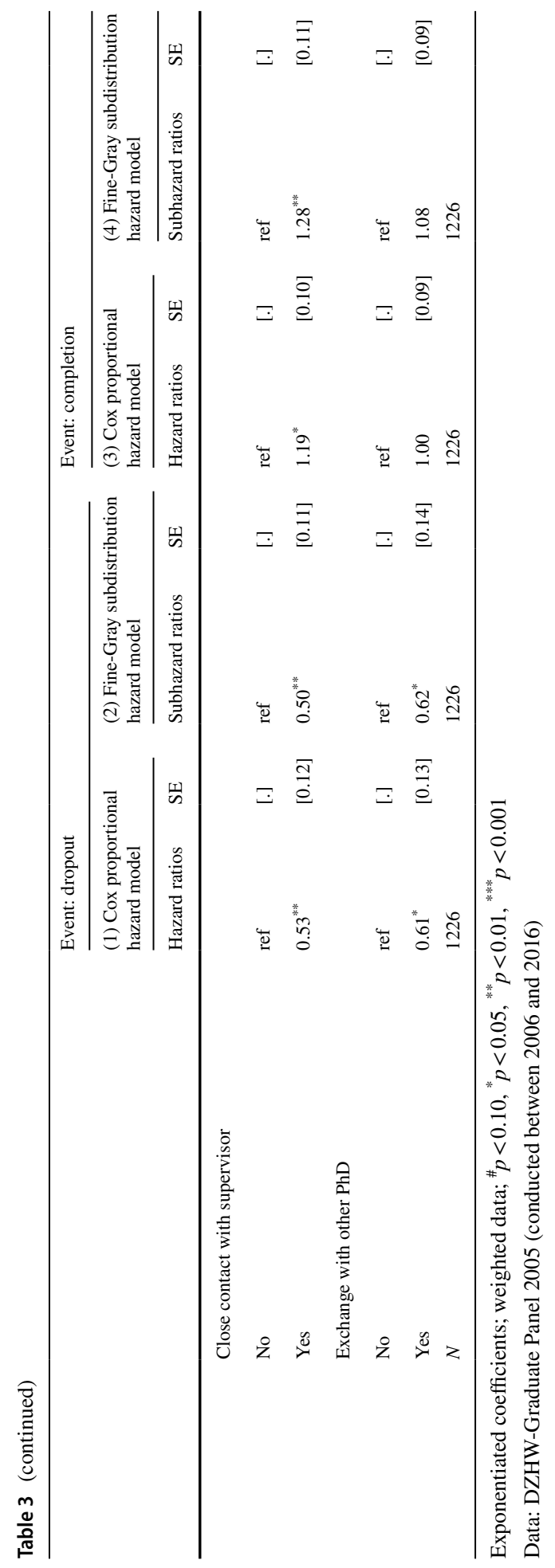


Acknowledgements We are grateful for valuable comments from Annabell Daniel.

Funding Funded by the Deutsche Forschungsgemeinschaft (DFG, German Research Foundation) 433155285. Open Access funding enabled and organized by Projekt DEAL.

Open Access This article is licensed under a Creative Commons Attribution 4.0 International License, which permits use, sharing, adaptation, distribution and reproduction in any medium or format, as long as you give appropriate credit to the original author(s) and the source, provide a link to the Creative Commons licence, and indicate if changes were made. The images or other third party material in this article are included in the article's Creative Commons licence, unless indicated otherwise in a credit line to the material. If material is not included in the article's Creative Commons licence and your intended use is not permitted by statutory regulation or exceeds the permitted use, you will need to obtain permission directly from the copyright holder. To view a copy of this licence, visit http://creativecommons.org/licenses/by/4.0/.

\section{References}

Ampaw, F. D., \& Jaeger, A. J. (2012). Completing the three stages of doctoral education: An event history analysis. Research in Higher Education, 53(6), 640-660.

Andersen, P. K., Geskus, R. B., de Witte, T., \& Putter, H. (2012). Competing risks in epidemiology: Possibilities and pitfalls. International Journal of Epidemiology, 41(3), 861-870.

Auriol, L. (2010). Careers of doctorate holders: Employment and mobility patterns. OECD Science (Technology and Industry Working Papers, No. 2010/04, Paris), https://doi.org/10.1787/5kmh8phxvvf5-en.

Austin, P. C., Latouche, A., \& Fine, J. P. (2020). A review of the use of time-varying covariates in the FineGray subdistribution hazard competing risk regression model. Statistics in Medicine, 39(2), 103-113.

Baillet, F., Franken, A., \& Weber, A. (2019). DZHW Graduate Panel 2005. Data and Methods Report on the Graduate Panel 2005. RDC-DZHW.

Bair, C. R., \& Haworth, J. G. (2004). Doctoral student attrition and persistence: a meta-synthesis of research. In J. C. Smart (Ed.), Higher education: Handbook of theory and research (Vol. 19, pp. 481534). Springer.

Becker, R., Haunberger, S., \& Schubert, F. (2010). Studienfachwahl als Spezialfall der Ausbildungsentscheidung und Berufswahl. Zeitschrift für Arbeitsmarktforschung, 42(4), 292-310.

Beekhoven, S., De Jong, U., \& Van Hout, H. (2002). Explaining academic progress via combining concepts of integration theory and rational choice theory. Research in Higher Education, 43(5), 577-600. https://doi.org/10.1023/A:1020166215457.

Booth, A. L., \& Satchell, S. E. (1995). The hazards of doing a PhD: An analysis of completion and withdrawal rates of British PhD students in the 1980s. Journal of the Royal Statistical Society. Series A (Statistics in Society), 158(2), 297-318. https://doi.org/10.2307/2983293.

Breen, R., \& Goldthorpe, J. H. (1997). Explaining educational differentials: Towards a formal rational action theory. Rationality and Society, 9(3), 275-305.

Castelló, M., Pardo, M., Sala-Bubaré, A., \& Suñe-Soler, N. (2017). Why do students consider dropping out of doctoral degrees? Institutional and personal factors. Higher Education, 74(6), 1053-1068. https:// doi.org/10.1007/s10734-016-0106-9.

Cleves, M., Gould, W., Gould, W. W., Gutierrez, R., \& Marchenko, Y. (2016). An introduction to survival analysis using Stata (Revised third ed.). Stata press.

Consortium for the National Report on Junior Scholars (2017). National Report on Junior Scholars. Statistical data and research findings on doctoral students and doctorate holders in Germany. Overview of Key Results. wbv.

Cooke, D. K., Sims, R. L., \& Peyrefitte, J. (1995). The relationship between graduate student attitudes and attrition. The Journal of Psychology, 129(6), 677-688.

Cyranoski, D., Gilbert, N., Ledford, H., Nayar, A., \& Yahia, M. (2011). Education: The PhD factory. Nature, 472, 276-279. https://doi.org/10.1038/472276a.

Dubois-Shaik, F., \& Fusulier, B. (2017). Understanding gender inequality and the role of the work/family interface in contemporary academia: An introduction. European Educational Research Journal, 16(2-3), 99-105. https://doi.org/10.1177/1474904117701143.

Ehrenberg, R. G., \& Mavros, P. G. (1995). Do doctoral students' financial support patterns affect their times-to-degree and completion probabilities? The Journal of Human Resources, 30(3), 581-609. 
Ehrenberg, R. G., Jakubson, G. H., Groen, J. A., So, E., \& Price, J. (2007). Inside the black box of doctoral education: What program characteristics influence doctoral students' attrition and graduation probabilities? Educational Evaluation and Policy Analysis, 29(2), 134-150. https://doi.org/10.3102/01623 73707301707.

Enders, J. (2004). Research training and careers in transition: A European perspective on the many faces of the Ph.D. Studies in Continuing Education, 26(3), 419-429. https://doi.org/10.1080/015803704200026 5935.

Euler, T., Trennt, F., Schaeper, H., \& Trommer, M. (2018). Werdegänge der Hochschulabsolventinnen und Hochschulabsolventen 2005: Dritte Befragung des Prüfungsjahrgangs 2005 zehn Jahre nach dem Abschluss. HIS: Forum Hochschule.

Federal Statistical Office (2019). Promovierendenstatistik: Analyse zu Vollständigkeit und Qualität der zweiten Erhebung - 2018. Statistisches Bundesamt.

Fine, J. P., \& Gray, R. J. (1999). A proportional hazards model for the subdistribution of a competing risk. Journal of the American Statistical Association, 94(446), 496-509.

Franz, A. (2018). Symbolischer Tod im wissenschaftlichen Feld. Eine Grounded-Theory-Studie zu Abbrüchen von Promotionsvorhaben in Deutschland. Springer VS.

Garcia-Quevedo, J., Mas-Verdú, F., \& Polo-Otero, J. (2012). Which firms want PhDs? An analysis of the determinants of the demand. Higher Education, 63(5), 607-620. https://doi.org/10.1007/ s10734-011-9461-8.

Geven, K., Skopek, J., \& Triventi, M. (2018). How to increase PhD completion rates? An impact evaluation of two reforms in a selective graduate school, 1976-2012. Research in Higher Education, 59(5), 529-552. https://doi.org/10.1007/s11162-017-9481-z.

Golde, C. M. (2005). The role of the department and discipline in doctoral student attrition: Lessons from four departments. The Journal of Higher Education, 76(6), 669-700. https://doi.org/10.1080/ 00221546.2005 .11772304 .

Groenvynck, H., Vandevelde, K., \& Van Rossem, R. (2013). The PhD track: Who succeeds, who drops out? Research Evaluation, 22(4), 199-209. https://doi.org/10.1093/reseval/rvt010.

Heineck, G., \& Matthes, B. (2012). Zahlt sich der Doktortitel aus? Eine Analyse zu monetären und nicht-monetären Renditen der Promotion. In N. Huber, A. Schelling, \& S. Hornbostel (Eds.), Der Doktortitel zwischen Status und Qualifikation (pp. 85-99). iFQ-Working Paper No. 12.

Hüther, O., \& Krücken, G. (2018). Higher education in Germany-recent developments in an international perspective (Vol. 49). Springer.

Jaksztat, S. (2017). Geschlecht und wissenschaftliche Produktivität. Erklären Elternschaft und wissenschaftliches Sozialkapital Produktivitätsunterschiede während der Promotionsphase? Zeitschrift für Soziologie, 46(5), 347-361. https://doi.org/10.1515/zfsoz-2017-1019.

Latouche, A., Allignol, A., Beyersmann, J., Labopin, M., \& Fine, J. P. (2013). A competing risks analysis should report results on all cause-specific hazards and cumulative incidence functions. Journal of Clinical Epidemiology, 66(6), 648-653. https://doi.org/10.1016/j.jclinepi.2012.09.017.

Lörz, M., \& Mühleck, K. (2018). Gender differences in higher education from a life course perspective: Transitions and social inequality between enrolment and first post-doc position. Higher Education, 77(3), 381-402. https://doi.org/10.1007/s10734-018-0273-y.

Lörz, M., \& Schindler, S. (2016). Soziale Ungleichheiten auf dem Weg in die akademische Karriere. Sensible Phasen zwischen Hochschulreife und Post-Doc-Position. Beiträgezur Hochschulforschung, 38(4), 14-39.

Lott, J. L., Gardner, S., \& Powers, D. A. (2009). Doctoral student attrition in the stem fields: An exploratory event history analysis. Journal of College Student Retention: Research, Theory \& Practice, 11(2), 247-266. https://doi.org/10.2190/CS.11.2.e.

Lovitts, B. E. (2001). Leaving the ivory tower: The causes and consequences of departure from doctoral study. Rowman \& Littlefield.

Lynch, K. D. (2008). Gender roles and the American academe: A case study of graduate student mothers. Gender and Education, 20(6), 585-605. https://doi.org/10.1080/09540250802213099.

Mainhard, T., Van Der Rijst, R., Van Tartwijk, J., \& Wubbels, T. (2009). A model for the supervisor-doctoral student relationship. Higher Education, 58(3), 359-373. https://doi.org/10.1007/ s10734-009-9199-8.

Maloshonok, N., \& Terentev, E. (2018). National barriers to the completion of doctoral programs at Russian universities. Higher Education, 77(2), 195-211. https://doi.org/10.1007/s10734-018-0267-9.

Mastekaasa, A. (2005). Gender differences in educational attainment: The case of doctoral degrees in Norway. British Journal of Sociology of Education, 26(3), 375-394. 
Mertens, A., \& Röbken, H. (2013). Does a doctoral degree pay off? An empirical analysis of rates of return of German doctorate holders. Higher Education, 66(2), 217-231. https://doi.org/10.1007/ s10734-012-9600-x.

Moss-Racusin, C. A., Dovidio, J. F., Brescoll, V. L., Graham, M. J., \& Handelsman, J. (2012). Science faculty's subtle gender biases favor male students. Proceedings of the National Academy of Sciences, 109(41), 16474-16479. https://doi.org/10.1073/pnas.1211286109.

Most, D. E. (2008). Patterns of doctoral student degree completion: A longitudinal analysis. Journal of College Student Retention: Research, Theory \& Practice, 10(2), 171-190. https://doi.org/10.2190/ CS.10.2.d.

Nünning, A., \& Sommer, R. (Eds.). (2007). Handbuch Promotion: Forschung-Förderung-Finanzierung. J.B. Metzler.

OECD. (2015). OECD Science, Technology and Industry Scoreboard 2015: Innovation for growth and society. OECD Publishing.

Schneider, M., \& Preckel, F. (2017). Variables associated with achievement in higher education: A systematic review of meta-analyses. Psychological Bulletin, 143(6), 565-600. https://doi.org/10.1037/bul00 00098.

Skopek, M., Triventi, M., \& Blossfeld, H.-P. (2020). How do institutional factors shape PhD completion rates? An analysis of long-term changes in a European doctoral program. Studies in Higher Education, https://doi.org/10.1080/03075079.2020.1744125.

Stock, W. A., Siegfried, J. J., \& Finegan, T. A. (2011). Completion rates and time-to-degree in economics PhD programs. American Economic Review, 101(3), 176-188. https://doi.org/10.1257/aer.101.3.176.

Tinto, V. (1993). Leaving College. Rethinking the causes and cures of student attrition (2nd ed.). The University of Chicago Press.

Trennt, F., \& Euler, T. (2019). Monetäre Erträge einer Promotion. Kölner Zeitschrift für Soziologie und Sozialpsychologie, 71(2), 275-308. https://doi.org/10.1007/s11577-019-00619-5.

Vassil, K., \& Solvak, M. (2012). When failing is the only option: Explaining failure to finish PhDs in Estonia. Higher Education, 64(4), 503-516. https://doi.org/10.1007/s10734-012-9507-6.

Visser, M. S., Luwel, M., \& Moed, H. F. (2007). The attainment of doctoral degrees at Flemish Universities: A survival analysis. Higher Education, 54(5), 741-757. https://doi.org/10.1007/s10734-006-9021-9.

Wollast, R., Boudrenghien, G., Van der Linden, N., Galand, B., Roland, N., Devos, C., et al. (2018). Who are the doctoral students who drop out? Factors associated with the rate of doctoral degree completion in universities. International Journal of Higher Education, 7(4), 143-156. https://doi.org/10.5430/ijhe. v7n4p143.

Wright, T., \& Cochrane, R. (2000). Factors influencing successful submission of PhD theses. Studies in Higher Education, 25(2), 181-195. https://doi.org/10.1080/713696139.

Publisher's note Springer Nature remains neutral with regard to jurisdictional claims in published maps and institutional affiliations. 